\title{
Machinery Parts Library Exhibition Room Based VIRTOOLS
}

\author{
Bin Shen*, Yuan Liu and Guoji Cai \\ Wuhan Donghu University, China, 430212 \\ ${ }^{*}$ Corresponding author
}

\begin{abstract}
Mechanical manufacturing technology courses need to master the basic characteristics of a large number of mechanical parts. However, the diversification of parts and the modernization of design are hard to satisfy the growing desire of students. This requires a new method to replace the traditional mold demonstration teaching. Virtual reality technology is a new technology in recent years. This paper studies the construction of exhibition room for mechanical parts library based on VIRTOOLS. The virtual exhibition hall can provide the advanced experimental environment and simulation means for the basic introduction of the common mechanical parts and the demonstration of the internal structure. It can cultivate the students' ability to understand the basic features of the common parts quickly. In this paper, a virtual exhibition system is designed based on the common mechanical parts. It provides an effective solution for the virtual display of mechanical parts.
\end{abstract}

Keywords—virtual display; VIRTOOLS; mechanical parts

\section{INTRODUCTION}

The process of mechanical manufacturing generally includes the mechanical process of parts and the assembly process of machines. When students majored in mechanical engineering carry out mechanical manufacturing technology, for a large number of mechanical parts, it is difficult to fully grasp the characteristics of parts from books and PPT. This makes it difficult for them to understand mechanical manufacturing technology thoroughly. Many good schools have purchased large quantities of teaching molds to demonstrate the actual parts. However, the diversification of parts and the modernization of design are hard to satisfy the growing desire of students. This requires a new method to replace the traditional mold demonstration teaching.

Virtual reality technology is a new technology in recent years. It uses a computer to generate a realistic threedimensional virtual world, which can bring people a sense of visual, listening and touching, and the user is as if they are in the world, freely observing and manipulating the virtual world and interacting with them naturally. In the virtual world established by VR technology, users are no longer restricted by time and space, and have a "immersive" experience in the sense of touch, hearing and vision. Many universities and scientific research institutions have successfully developed virtual laboratory, roaming system, virtual digital library and digital exhibition hall by using virtual reality technology.

This paper studies the construction of exhibition room for mechanical parts library based on VIRTOOLS. The virtual exhibition hall can provide the advanced experimental environment and simulation means for the basic introduction of the common mechanical parts and the demonstration of the internal structure. It can cultivate the students' ability to understand the basic features of the common parts quickly. The application of virtual reality technology in the construction of mechanical parts library is of great significance to the development of virtual exhibition system for the replacement of practical teaching in machinery specialty teaching and research section. It effectively solves the problems of expensive mechanical parts, restrictions on site, quantity and type, and low training efficiency. Therefore, this paper takes the common mechanical parts as the object, designs a virtual exhibition system, and provides an effective solution for the virtual display of mechanical parts.[1-10].

\section{THE OVERALl CONSTRUCTION OF THE SYSTEM}

According to the system function requirement analysis and the selected realization way, the virtual simulation display system is composed of four parts: solid introduction, virtual display and demonstration. The software design of the system is as follows:

The system uses Visual C++6.0 software and the Virtools software of Dassault company of France as the development platform of the system. Using Solidworks 3D design software and 3dsmax as modeling and animation generating tools, Access for the system database to store sample parts library, part coordination library and some service samples.

Virtual reality simulation is the omnidirectional simulation under the virtual environment, which is closely related to the theme of industrial robots. This paper mainly studies the non immersive simulation technology based on Virtools software combined with the three-dimensional maintenance model. The equipment model itself has a large number of parts. Generally, it belongs to large assembly. The 3D modeling technology provided by Solidworks software has a good effect in dealing with large assembly.

\section{ESTABLISHMENT OF A MECHANICAL PART LIBRARY}

The first level of the comprehensive experiment is a threedimensional virtual scene composed of six experimental stations. The work and the problems to be paid attention to on the spot are as follows: (1) setting up a mobile camera as the eye and allowing the learners to roam the whole laboratory. The camera, that is, the rotation of the "eye" should conform to 
the real human eye. In order to enhance the learner's "immersion" and create a "immersive" effect. (2) avoid the occurrence of "through the wall". To set a collision effect on the objects in the experimental scene. (3) avoid the "lost" of the learners. Let the learner arrive at the destination laboratory by directly clicking the map area. (4) introduce the "host". In every experiment scene, the role should be set. On the one hand, the learner can give the learner's instructions, the experimental knowledge, and on the other hand, it can also prompt the students to correct their mistakes and strengthen them in the course of the experiment. The learning effect of the learner.
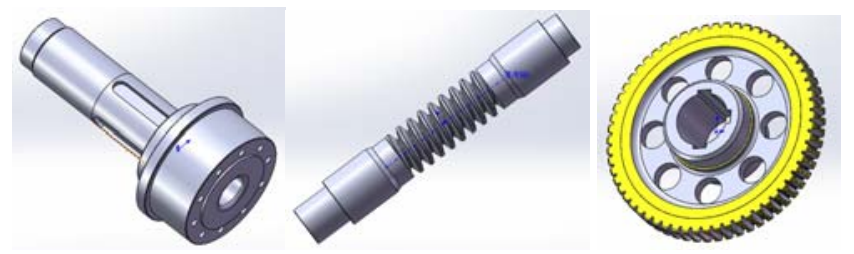

FIGURE I. WORM SHAFT, WORM, TURBINE
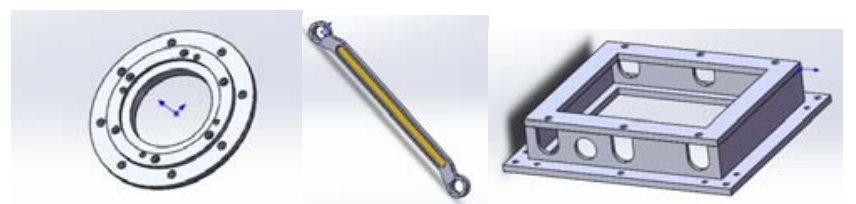

FIGURE II. FLANGES, PEDESTAL, CONNECTING ROD

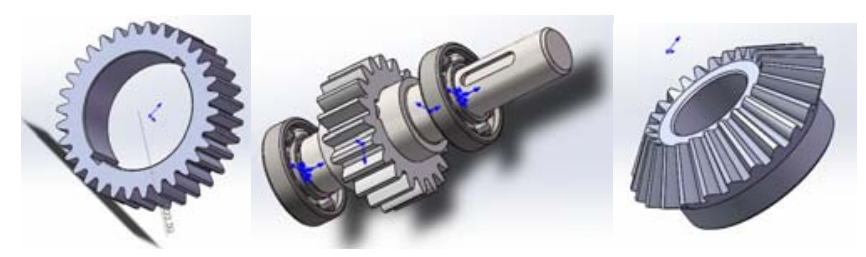

FIGURE III. GEAR SERIES

In order to cooperate with the teaching of mechanical manufacturing technology, the common mechanical parts such as ball screw pair, gear pair and screw cylinder pair are selected. The best interactive mode of the system is a real time interactive 3D display based on virtual reality technology, which needs to be implemented by introducing the 3D model data into the virtual reality tool. The implementation techniques of the system are as follows: the 3D model of parts is built based on Solidworks, the rendering effect of material is added by 3Dmax, and its virtual display and interaction are realized on the basis of Virtools. The specific process is: (1) using Solidworks and 3DMAX software to build 3D model, save .Nmo format into Virtools software; (2) add behavior modules in Virtools software, edit scripts, add interface design elements to realize the predetermined interactive function; (3) system release. The three-dimensional modeling of mechanical parts is shown in Figure 1 to Figure 3.

\section{Virtual Display of Model Display}

VIRTOOOLS software completes the virtual display of the model by controlling the rotation of the light and camera. Before entering the virtual display of the mechanical parts, the system first introduces the related parts in the way of the opening animation, and the main idea is to display the main parts in the part library in the middle of the screen. The specific program design is shown in Figure 4.

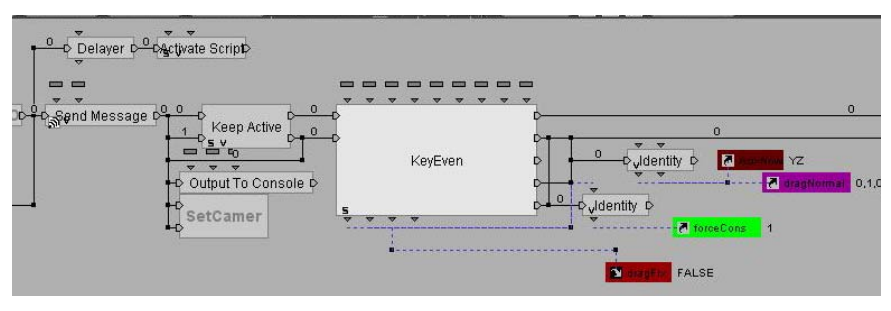

FIGURE IV. VIRTUAL DISPLAY MAIN INTERFACE OPENING ANIMATION SETTING

Users can control the conversion of mouse triggering behavior by keyboard. So, when the user needs to view the appearance and internal composition of the mechanical parts from different angles, there are two ways to realize it, that is, the method of using the keyboard to control the camera or the mouse to trigger the camera animation. However, these two methods can not run at the same time, that is to say, when the keyboard is used to control the camera, it is necessary to turn off the mouse to trigger the camera action, and vice versa. The specific scripting process is shown in Figure 5.

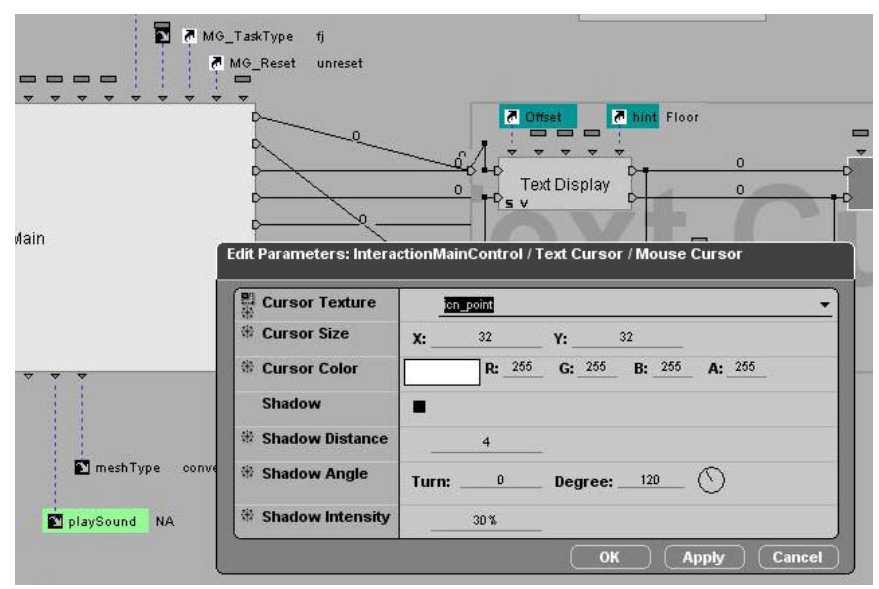

FIGURE V. CAMERA INITIAL SETTING

The system controls the movement of the camera through the mouse, so that the user can immerse himself in the situation. The specific scripting process is shown in Figure 6.

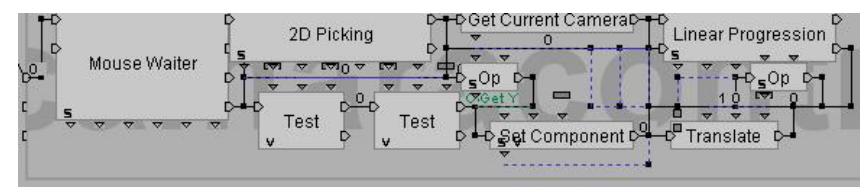

FIGURE VI. MOUSE DRIVE CAMERA MOTION

Complex equipment through three-dimensional structure, sectional view and so on can well display the structural features of the equipment, connection, and can also master the movement through the way of animation. This will lay a solid foundation for a comprehensive grasp of the structure of the equipment. The demonstration program of virtual assembly and virtual maintenance is established through Virtools, and the existing knowledge points are demonstrated. It makes the 
students' operation to follow. The realization of this part is mainly to grasp the conversion of camera lens. Light angle of view and equipment material.The handover of view can be set up in different locations. As shown in Figure 7.

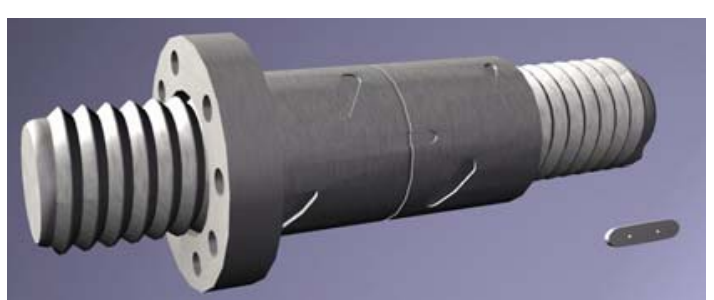

FIGURE VII. ANIMATION OF BALL SCREW CUSHION ADJUSTMENT CLEARANCE

\section{CONCLUSION}

Compared with the traditional equipment introduction, virtual display has considerable advantages in improving training flexibility, breaking through training conditions and reducing equipment maintenance costs. Virtools 5 software is powerful and easy to operate. It is very suitable for the development of similar systems. Based on the analysis and summary of the virtual reality technology and the traditional product display mode, this paper puts forward the basic architecture of the virtual product display system, gives the corresponding design process of the product display system, and expounds the implementation process of the presented display system through an example. Through the test of the system, the system has basically achieved the expected effect. It can show the product from different angles and simulate the various functions of the product. It can also play a good role in propaganda and improve the competitiveness of the enterprise itself. However, there are still some shortcomings in the system. Due to the limitation of the server module, the multi-user online control system has not yet been implemented. I believe that with the rapid development of information technology, new technology will bring more surprises to the society.

\section{REFERENCES}

[1] T. M. Cheng, "A fast parametric deformation mechanism for virtual reality applications”[J], Computer \& Industrial Engineering,2008,10(10): 18-26.

[2] Pan Zhigeng, Cheok Adrian David. Virtual Reality and Mixed Reality for Virtual Learning Environments[J]. Computer \& Graphics, 2006, 30(1): 20-28.

[3] Li J R, Khoo P. Tor B. Desktop Virtual Reality for Maintenance training: An Object Oriented Prototype System(V-REALISM)[J]. Computerin Industry, 2003, 52(2): 109-125.

[4] Christopher M C, David C. Virtools Dev User Guide: Version 4.0[z]. Virwols SA, 2006.

[5] Virtools 5.0 Online Heferenee.

[6] Wutthikornthanawat w'Jinuntuya P,Rongviriyapanieh S, et a1. Multiuser tangible interface for public participation development of low-cost housing project design and planning[C]. Proeeedings of the 12th International Conference on Computer-Aided Architectural Design Research in Asia-Digitization and Globalizatin, 2007: 37-43.

[7] Wang Xi, An Yang. Development ofgame software based on Virtools[J]. Control and Management, 2007, 5(5): 160-162.
[8] Li Xunxiang, Chen Dingfang, Wang Le, et a1. A development framework for V'trtools-based DVR driving systemiC]. Computer Supported Cooperative Work in Design,2007: 188-196.

[9] Pan VLin Z,Hu Z, et a1. Research on distributed multi. screendis. play technique based on Virtools[C]. 7th Intemational Conferenee on Computer-Aided Industrial Design and Conceptual Design,2006: 1-6.

[10] D. U. Silverthom. Teaching and learning in the interactive classroom [J]. Advances in Physiology Education, 2006, 12(30): 135-140. 